\title{
Establishment of a continuous model system to study Helicobacter pylori survival in potable water biofilms
}

\author{
N.F. Azevedo ${ }^{\star, \star \star}$, M. J. Vieira ${ }^{\star \star}$ and C.W. Keevil ${ }^{\star}$ \\ * Environmental Healthcare Unit, School of Biological Sciences, University of Southampton, Southampton, \\ UK \\ *^ Centro de Engenharia Biológica, Universidade do Minho, 4700-057 Braga, Portugal
}

\begin{abstract}
Close association of the pathogen Helicobacter pylori in drinking water biofilms has been suggested. Using a two-stage water model, the survival and development of the pathogen in potable water biofilms was monitored. Filter sterilized tap water was used as the growth medium and the inoculum consisted of a naturally occurring consortium of microorganisms. Biofilms were generated on removable stainless steel coupons that were placed in the second vessel. Novel technology peptide nucleic acid (PNA) molecular probes were used to detect and locate the pathogen in the biofilms. The PNA-labelled oligonucleotide probes were highly specific, and complementary to the helix 6 region of $H$. pylori $16 \mathrm{~S}$ rRNA. The pathogen was tracked in the biofilms using epifluorescence microscopy and episcopic differential interference contrast microscopy. Results show that $H$. pylori can successfully incorporate within biofilms and its presence was detected for up to five days after inoculation. PNA probes provided an easy and quick way of performing fluorescence in situ hybridisation assays in heterogeneous biofilms.
\end{abstract}

Keywords Biofilm; episcopic differential interference contrast microscopy; Helicobacter pylori; peptide nucleic acids

\section{Introduction}

Helicobacter pylori is a Gram-negative, microaerophilic, flagellated bacteria, whose relatedness to organisms of the genus Campylobacter led scientists to first name it as Campylobacter pyloridis (Warren and Marshal, 1983). However, the bacterium revealed important differences at the biochemical, morphological and genetic level to other Campylobacter spp. and was eventually renamed (Goodwin et al., 1989).

Infection with $H$. pylori leads to several gastrointestinal diseases such as gastritis, peptic and duodenal ulcers (Taylor and Blaser, 1991), gastric carcinomas and mucosa-associated lymphoid tissue tumours (Moran, 1997). In Western countries rates of infection are as high as $60 \%$ by age 65 , while in developing countries the prevalence of infection can be as high as $90 \%$ by 20 years of age (Foreman and Webb, 1993); however, most infections are asymptomatic. Although the mode of transmission remains a subject open to discussion, $H$. pylori has already been detected in Peruvian drinking water (Hulten et al., 1996), tap and well water in Japan (Sasaki et al., 1999), and, more recently, identified in a water distribution pipe biofilm in Scotland using a nested PCR technique (Park et al., 2001). This information points to the necessity of studying $H$. pylori in water systems, especially in biofilms, where the bacteria can have better chances of survival in the microenvironments generated by the heterogeneous structure and activity of the complex consortia (Keevil, 2001a). The public concern about the survival of this microorganism in water was acknowledged by the United States Environmental Protection Agency by including it in their Contaminant Candidate List in their 1998 report (US EPA, 1998).

Peptide nucleic acid (PNA) is a synthetic DNA analogue, where a polyamide formed by repetitive units of $N$ - (2-aminoethyl) glycine replaces the negatively charged sugar phosphate backbone of DNA and RNA. Because both structures have the same interbase 
spacing, PNA/DNA or PNA/RNA hybrids of complementary nucleic acid sequences can be formed and PNA oligonucleotides can be used as a probe. In fact, PNA probes are better for targeting highly structured nucleic acids, like rRNAs, since hybridisation with PNA probes can be performed efficiently under low salt concentrations. These conditions destabilize the secondary structures of the rRNA resulting in an improved access to the target sequences (Stefano and Hyldig-Nielsen, 1997). Other advantages of the use of PNA oligonucleotides include a faster hybridisation time, resistance to nuclease and protease attack, and higher specificity and sensitivity. PNA has already been successfully used for in situ detection of Escherichia coli in water (Prescott and Fricker, 1999), however, no studies have been made with this technology in the area of biofilms.

Microscopy examination of entire biofilms has significantly increased our understanding of the spatial organisation that occurs within them and on the surfaces supporting their environment (Lawrence et al., 1991; Rogers et al., 1991). The information that may be gained includes measurement of the depth of biofilm (Bakke and Olson, 1986) and identification of specific species within the biofilm consortia using immunolabels (Rogers and Keevil, 1992).

\section{Methods}

H. pylori culture

Helicobacter pylori NCTC 11637 was cultured in Columbia Agar (Oxoid, Basingstoke, UK) supplemented with $7 \%$ (vol/vol) of defribinated horse blood (Oxoid) and incubated at $37^{\circ} \mathrm{C}$ under microaerophilic conditions using Campygen (Oxoid) gas packs in a closed container.

\section{Two-stage model system}

The two-stage model used, which has been described previously (Keevil, 2001b), consisted of two $1 \mathrm{~L}$ glass vessels linked in series to simulate conditions found in a water system. In both vessels the top plate and the sample port hood were made of titanium, in order to eliminate extraneous iron from the culture. The first vessel (seed) was fed by filter-sterilized tap water to produce a dilution rate of $0.05 \mathrm{~h}^{-1}$ and, to ensure reproducibility, the conditions in this vessel remained constant. The heterotrophic consortium of microorganisms collected during the first filtration of the tap water was utilised as the inoculum for the seed vessel. A constant $0.05 \mathrm{~h}^{-1}$ flow from this vessel was supplied into a second vessel, which was used to grow biofilms. Additional sterile water was added to this biofilm-generating vessel to produce an overall dilution rate of $0.2 \mathrm{~h}^{-1}$. Effluent from the second vessel was collected in a waste container. The temperature in both vessels was maintained at $30^{\circ} \mathrm{C}$ using an external electrical pad controlled by a proportional integral derivative unit system. The stirrer speed was $300 \mathrm{rpm}$ in both vessels and ensured liquid homogenisation as well as sufficient oxygen concentration in the water (Figure 1). Regular sampling was performed in both fermentors, to enumerate planktonic bacteria CFU in R2A agar.

\section{Biofilm growth and inoculation of the pathogen}

Coupons of stainless steel were made with an area of $1.2 \mathrm{~cm}^{2}$, with a $1 \mathrm{~mm}$ hole that allowed them to be suspended from titanium wire (three coupons per set). Before these coupons were inserted in the second vessel they were immersed in acetone for removal of any organic carbon compounds attached to them. After the formation of the biofilm, coupons were either directly used for microscopy observations or scraped for heterotrophic plate counting on R2A agar using appropriate dilutions.

After allowing the growth of biofilms for one week, the model was inoculated with $H$. 

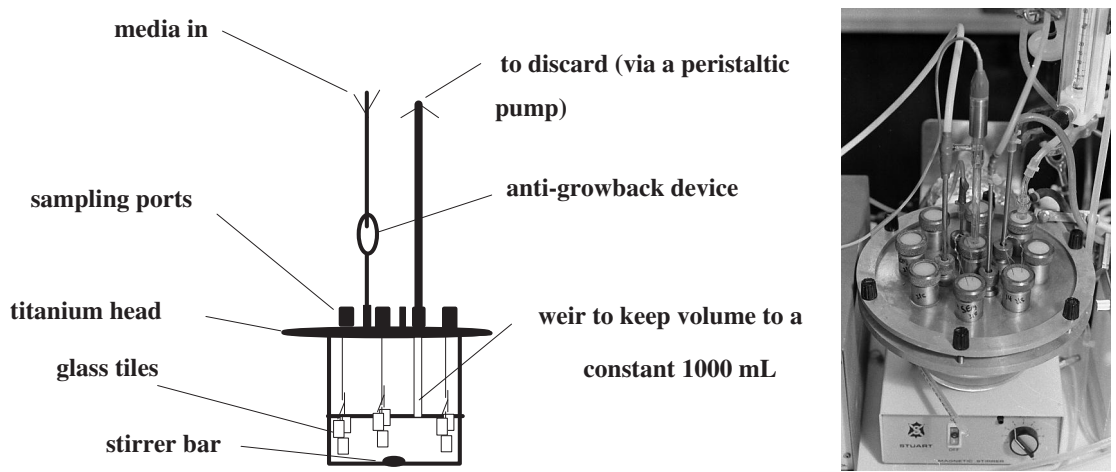

Figure 1 Diagram (left) and picture (right) of the second vessel of the model biofilm system with multiple assemblages of coupons suspended from rigid titanium wire inserted through silicone rubber bungs in the top ports. The weir system was used to maintain the volume at the required level

coupons from the fermenter was taken just before inoculation (control) and $1 \mathrm{~h}, 2 \mathrm{~h}, 5 \mathrm{~h}$, $24 \mathrm{~h}$ and 5 days after inoculation, and the pathogen was tracked using peptide nucleic acid FISH.

\section{Design of PNA oligonucleotide probes}

A PNA oligonucleotide probe directed against the 16S rRNA molecule was synthesized (Oswell, UK) for the detection of $H$. pylori NCTC 11637. The oligonucleotide used was complementary to the 19 base pair primer ACT-1 (Thoreson et al., 1994) that was tested against related and non-related bacteria and was found to have insignificant homology to them. Because PNA achieve optimal combination of specificity and binding strength between 12 and 18 bases long, one base was taken from the ACT-1 primer. The sequence used was therefore 5'-(TAATCAGCACTCTAGCAA)-3', with a fluorescent carboxyfluorescein molecule connected in the $5^{\prime}$ terminal. An Advanced BLAST search of the Genbank nr-database showed that this new oligonucleotide differed by at least 2 bases from the sequences of other bacteria species. Bacteria isolated from the system using R2A medium were also found not to hybridise with the probe.

\section{PNA hybridisation procedure}

The hybridisation procedure was done according to Stender et al. (1999) with slight modifications. All chemicals were obtained from Sigma, unless otherwise stated. Prior to hybridisation, the coupons were immersed in $90 \%$ ethanol for $10 \mathrm{~min}$, and left to air-dry. The coupons were then covered with the hybridisation solution, which consisted of $10 \%$ (wt/vol) of dextran sulfate, $10 \mathrm{mM} \mathrm{NaCl}, 30 \%$ (vol/vol) formamide, $0.1 \%$ (wt/vol) sodium pyrophosphate, $0.2 \%(\mathrm{wt} / \mathrm{vol})$ polyvinylpirrolidone, $0.2 \%$ (wt/vol) FICOLL, $5 \mathrm{mM}$ disodium EDTA, $0.1 \%$ (vol/vol) Triton X-100, $50 \mathrm{mM}$ of Tris $\mathrm{HCl}(\mathrm{pH} 7,5)$ and $200 \mathrm{nM}$ of the PNA probe (Oswell, Southampton, UK), for $90 \mathrm{~min}$ at $55^{\circ} \mathrm{C}$. Following hybridisation, coupons were washed in a pre-warmed solution containing $5 \mathrm{mM}$ Tris Base, $15 \mathrm{mM} \mathrm{NaCl}$ and $1 \%(\mathrm{vol} / \mathrm{vol})$ of Triton $\mathrm{X}(\mathrm{pH} 10)$ at $55^{\circ} \mathrm{C}$ for $30 \mathrm{~min}$. The coupon was then allowed to air dry and examination under the microscope occurred in the following $72 \mathrm{~h}$.

\section{Microscopic examination}

Biofilms were visualized using episcopic differential interference contrast microscopy and fluorescence microscopy, using the microscope especially designed for the study of biofilms (Keevil and Walker, 1992). This was equipped with a FITC filter sensitive to the PNA probe. 


\section{Results}

After the two-stage model was operated for 20 days in continuous mode, the planktonic heterotrophic plate count numbers of bacteria recovered on $\mathrm{R} 2 \mathrm{~A}$ for both vessels appeared to stabilize around $8.5 \times 10^{5}-2.1 \times 10^{6} \mathrm{CFU} / \mathrm{ml}$ in the first vessel, and $6.5 \times 10^{5}-8.5 \times 10^{5}$ $\mathrm{CFU} / \mathrm{ml}$ in the second one. Different types of colonies, with white, yellow, pink and orange pigmentation were present. Most types of these colonies could also be identified in biofilms on coupons when recovered and plated onto R2A.

For the hybridisation experiments, there was no evidence for non-specific binding of the PNA probe to the general heterotrophic microflora prior to the introduction of $\mathrm{H}$. pylori. However, the control without the PNA probe exhibited some fluorescence in several areas (Figure 2). This autofluorescence could also be identified after the inoculation of H. pylori and made detection of the pathogen more difficult because the autofluorescence was detected by the FITC channel of the microscope, as well as in the TRITC and DAPI channels. The coupling of the EF/EDIC images allowed the correlation of the fluorescence with the presence of stacks or fronds of biofilm, especially with the extracellular polymers.

The design of the microscope allowed the focussing at the base and top of the stacks to determine their height; typically, they rose between 50-100 $\mu \mathrm{m}$ from the substratum. Nevertheless, H. pylori could still be easily detected in the basal layer of the biofilm, and adjacent to the stacks, where the effects of the autofluorescence could not be detected. Spiral forms of the bacteria, ranging from 2 to $4 \mu \mathrm{m}$ long were still identified after 5 days of the experiment (Figure 3). Coccal and U-shaped cell morphologies were also detected throughout the experiment. All types exhibited a strong signal with the 16S rRNA PNA probe in the FITC channel; there was no fluorescence in the TRITC channel, suggesting that the probe was specific for H. pylori. These data indicate that there was a high content of RNA and ribosomes in $H$. pylori, and that the cells were still viable after 5 days in the biofilm.

\section{Discussion}

The two-stage system provides the steady state growth of planktonic and biofilm communities. Although these communities are very complex, the bacterial numbers in the fermenters did not vary very much, once the steady state was reached. This system therefore provides a convenient means to obtain reproducible data for biofilm development and colonisation by pathogens such as $H$. pylori.

This study represents the first reported use of PNA oligonucleotides for in situ detection of microorganisms in biofilms, and offers an efficient alternative to conventional DNA approaches. PNA technology seems to be easily adapted to study pathogens in biofilms.

The presence of autofluorescing stacks did not allow for an easy detection of the PNA-labelled pathogen within the structure. Autofluorescence of microorganisms and of

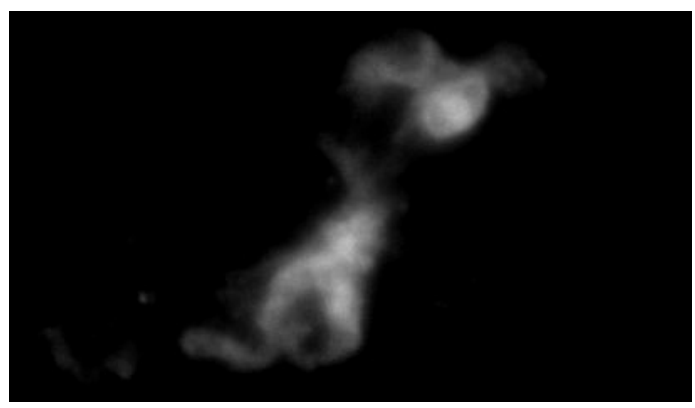

Figure 2 Epifluorescence microscopy image showing a control stack from a biofilm, exhibiting autofluorescence in the FITC channel 

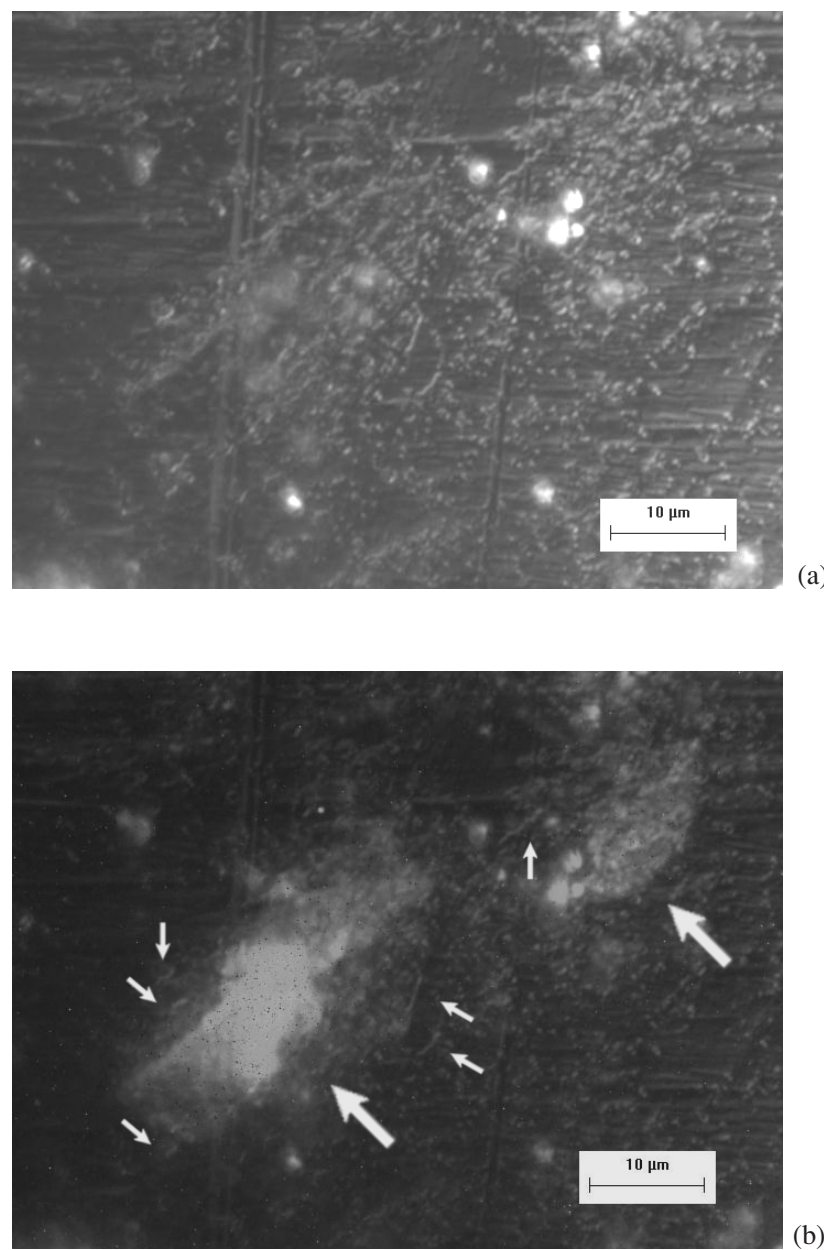

a)

(b)

Figure 3 Images of a biofilm from a coupon removed from the second vessel 5 days after the inoculation with $H$. pylori (a) DIC image showing the metal surface; (b) the EF counterpart of the same section showing the positive identification of several spiral shaped bacteria (small arrows) and autofluorescence of some stacks (large arrows)

chemical compounds has been previously reported, but we could not find in the literature any reference to natural autofluorescence in biofilms. Further studies will be conducted to explain this fluorescence, which is thought to be related to the presence of very low concentrations of some compound present in the local municipal water supply that is able to attach to and concentrate within the exopolymeric substances of the biofilm.

It is notable that $H$. pylori could still be easily identifiable by both PNA and characteristic morphology in the basal layer of the biofilm, especially close to the stacks. This suggests that like Legionella pneumophila and Campylobacter jejuni it is a motile microaerophile which migrates to low redox zones in heterogeneous biofilms (Keevil, 2001a,b). All three types of $H$. pylori morphology were identified by the PNA probe. That spiral forms were still detected after 5 days may be of great importance to public health, as spiral shaped bacteria are usually associated with a more viable form of the bacteria. This might suggest the pathogen can survive, at least transiently, in mains water supplies posing a risk of waterborne infection to the human population. This would be exacerbated if the biofilm provided some protection against routine chlorination practice, creating a safe heaven for the pathogen. 


\section{Conclusions}

H. pylori can successfully incorporate within biofilms and its spiral shaped form can be detected for up to five days after inoculation, bringing new concerns to water supply public health policy. This study represents the first reported use of PNA oligonucleotide probes in heterogeneous biofilms and concludes that this new technology provides an easy and quick way of performing fluorescence in situ hybridisation (FISH) assays in these types of structures.

\section{Acknowledgements}

This work was supported by the Portuguese Institute Fundação para a Ciência e Tecnologia (PhD grant SFRH/BD/4705/2001 and Project POCTI/35849/ESP/2000). The authors would also like to thank Henrik Stender for some very useful help on peptide nucleic acids.

\section{References}

Bakke, R. and Olsson, P. (1986). Biofilm thickness measurements by light microscopy. J. Microbiol. Methods, 5, 93-98.

Foreman, D. and Webb, P. (1993). Geographical distribution and association with gastric cancer. In: Helicobacter pylori infection, T.C. Northfield, M. Mendell and P.M. Goggin (eds.), Kluwer Academic Publishers, Dordrecht/Boston/London, pp. 11-20.

Goodwin, C.S., Armstrong, J.A., Chilvers, T., Peters, M., Collins, M.D., Sly, L., McConnel, W. and Harper, W.E.S. (1989). Transfer of Campylobacter pylori and Campylobacter mustelae to Helicobacter gen. nov. as Helicobacter pylori comb. nov. and Helicobacter mustelae com. nov., respectively. Int. J. Syst. Bacteriol., 39, 353-365.

Hulten, K., Han, S.W., Enroth, H., Klein, P.D., Opekun, A.R., Gilman, R.H., Evans, D.G., Engstrand, L., Graham, D.Y. and El-Zaatari, F.A. (1996). Helicobacter pylori in the drinking water in Peru. Gastroenterology, 110, 1031-1035.

Keevil, C.W. and Walker, J.T. (1992). Nomarski DIC microscopy and image analysis of biofilms. Binary, 4, 93-95.

Keevil, C.W. (2001a). Pathogens in environmental biofilms. In: The Encyclopaedia of Environmental Microbiology, G. Bitton (ed.), Wiley, New York, in press.

Keevil, C.W. (2001b). Continuous culture methods to study pathogens in biofilms. Methods Enzymol., 334, $104-122$.

Lawrence, J.R., Korber, D.R., Hoyle, B.D., Costerton, J.W. and Caldwell, D.J. (1991). Optical sectioning of microbial biofilms. J. Bacteriol., 173(20), 6558-6567.

Moran, A.P. (1997). Pathogenesis of gastric Helicobacter pylori. Trends Microbiol., 5, 262-263.

Park, S.R., Mackay, W.G. and Reid, D.C. (2001). Helicobacter sp. recovered from drinking water biofilm sampled from a water distribution system. Wat. Res., 35(6), 1624-1626.

Prescott, A.M. and Fricker, C.R. (1999). Use of PNA oligonucleotides for the in situ detection of Escherichia coli in water. Molecular Cellular Probes, 13(4), 261-168.

Rogers, J., Lee, J.V., Dennis, P.J. and Keevil, C.W. (1991). Continuous culture biofilm model for the survival and growth of Legionella pneumophila and associated protozoa in potable water systems. In Health Related Water Microbiology (eds. R. Morris et al.), IAWPRC, London, 192-200.

Rogers, J. and Keevil, C.W. (1992). Immunogold and fluorescein immunolabelling of Legionella pneumophila within an aquatic biofilm visualised by using episcopic differential interference contrast microscopy. Appl. Environ. Microbiol., 58(7), 2326-2330.

Sasaki, K., Tajiri, Y., Sata, M., Fujii, Y., Matsubara, F., Zhao, M., Shimizu, S., Toyonaga, A. and Tanikawa, K. (1999). Helicobacter pylori in the natural environment. Scnd. J. Infect. Dis., 31, 275-279.

Stefano, K. and Hyldig-Nielsen, J.J. (1997). Diagnostic applications of PNA oligomers. In: Diagnostic gene detection and quantification technologies. IBC Library series publication \#948 (ed.), International Business Communication, Southborough, MA, 19-37.

Stender, H., Lund, K., Petersen, K., Rasmussen, O., Hongmanee, P., Miorner, H. and Godtfredsen, S. (1999). Fluorescence in situ hybridization assay using peptide nucleic acid probes for differentiation between tuberculous and nontuberculous mycobacterium species in smears of mycobacterium cultures. J. Clin. Microbiol., 37(9), 2760-2765.

Taylor, D.N. and Blaser, M.J. (1991). The epidemiology of Helicobacter pylori infection. Epidemiol. Rev., $13,42-58$.

Thoreson, A.-C.E., Borre, M.B., Andersen, L.P., Elsborg, L., Holck, S., Conway, P., Henrichsen, J., Vuust, J. and Krogfelt, K.A. (1994). Development of a PCR-based technique for detection of Helicobacter pylori. FEMS Immunol. Med. Microbiol., 10(3-4), 325-333.

United States Environmental Protection Agency (1998). Announcement of the Drinking Water Contaminant Candidate List, Fed. Register, 63(40), pp. 10274-10287.

Warren, J.R. and Marshall, B. (1983). Unidentified curved bacilli on gastric epithelium in active chronic gastritis. Lancet, 1, 1273-1275. 